Pijls, W. and Bruin, A. de (1994). Generalizing Alpha-Beta. Advances in Computer Chess 7 (eds. H.J. van den Herik, I.S. Herschberg, and J.W.H.M. Uiterwijk), pp. 219-236, University of Limburg, Maastricht, The Netherlands. ISBN 90-6216-1014.

Reinefeld, A. (1989). Spielbaum Suchverfahren. Volume Informatik-Fachberichte 200. Springer-Verlag.

Reinefeld, A. (1994). A Minimax Algorithm Faster than Alpha-Beta. Advances in Computer Chess 7 (eds. H.J. van den Herik, I.S. Herschberg, and J.W.H.M. Uiterwijk), pp. 237-250, University of Limburg, Maastricht, The Netherlands. ISBN 90-6216-1014.

Reinefeld, A., Schaeffer, J., and Marsland, T. (1985). Information Acquisition in Minimal Window Search. Proceedings of the $9^{\text {th }}$ IJCAI, pp. 1040-1043.

Roizen, I. and Pearl, J. (1983). A Minimax Algorithm Better than Alpha-Beta? Yes and No. Artificial Intelligence, Vol. 21, pp. 199-230. ISSN 0004-3702.

Schaeffer, J. (1989). The History Heuristic and Alpha-Beta Search Enhancements in Practice. IEEE Transactions on Pattern Analysis and Machine Intelligence, Vol. 11, No. 11, pp. 1203-1212.

Stockman, G. (1979). A Minimax Algorithm Better than Alpha-Beta? Artificial Intelligence, Vol. 12, No. 2, pp. 179-196. ISSN 0004-3702.

Weill, J.C. (1990). Experiments with the NegaC* Search. Heuristic Programming in Artificial Intelligence 2: the second Computer Olympiad (eds. D.N.L. Levy and D.F. Beal), pp. 164-188. Ellis Horwood, Chichester, UK. ISBN 0-13-382615-5.

Weill, J.C. (1992). The NegaC* Search. ICCA Journal, Vol. 15, No. 1, pp. 3-7.

\title{
ACKNOWLEDGEMENT OF OUR 1994 REFEREES
}

The Editors of the ICCA Journal gratefully recognize the referees for having provided their many useful scientific comments and having volunteered their cooperative guidance in the past year. In gratitude, we list them:
H. Bal
H. Goeman
J. Romein
M.A. Bramer
T.A. Marsland
J. Schaeffer
I. Bratko
J. Nievergelt
K. Thompson
R. Feldmann
A. Reinefeld

\section{ICCA PROGRAMMERS' CONTACTS}

\author{
Don Beal
}

London / England

The ICCA from time to time receives requests from members writing their own chess programs, asking to be put into contact with other chess programmers.

The ICCA is willing to create and maintain a list of members who are interested in being contacted for this purpose. There will be two lists: an email list and a postal list. Each list will be accessible to its entrants. If you would like to be entered on either or both, send email to icca@dcs.qmw.ac.uk or post to Don Beal at the address given on the inside front cover.

Requests to join the postal list must be accompanied by an addressed envelope (it need not be stamped). The envelope will serve for sending the list when compiled.

1 Department of Computer Science, Queen Mary and Westfield College, Mile End Road, London E1 4NS, England. Email: icca@dcs.qmw.ac.uk. 